\title{
DE PINTURA VALENCIANA: \\ Bartolomé Bermejo, Rodrigo de Osona, El Maestro de Artés, Vicent Macip y Joan de Joanes
}

\author{
POR . \\ Ximo Company \\ Universidad de Lérida \\ Lluïsa Tolosa \\ Universidad Politécnica de Valencia
}

\begin{abstract}
This work is a revision of some atributions about Valencian painting of XV and XVI centuries, especially paintings by Bermejo, the Master of Artés, Macip and Joanes. We can point out the new interpretation of Joan de Joanes who for convincing documental and stylistic reasons is considered the author of a part of the work formerly atributed to his father Vicent Macip.
\end{abstract}

De todos es conocido el importante rol de la escuela valenciana en la génesis y el desarrollo de la pintura española del Renacimiento. Grandes maestros e importantes tablas vieron la luz en la Valencia de 1500, aspectos todos que a lo largo de los años han recibido la debida consideración por parte de los especialistas. En este escrito nos gustaría verter un poco más de luz sobre algunas tablas de pintura valenciana de los siglos XV y XVI, e iluminar con ella, a su vez, el perfil de algunos maestros fundamentales de dicha época. Las importantes personalidades, por ejemplo, de Vicent Macip y su hijo Joan de Joanes nos parece que se encuentran en un óptimo momento de nueva comprensión y reinterpretación historiográfica, tal y como tratará de exponerse en el presentre escrito.

Por otro lado, consideramos saludable reorientar algunas de las atribuciones de los últimos años, por cuanto, a nuestro criterio, no siempre se ha atinado en ellas. Nos inspiramos para ello en algunos de los escritos que sobre pintura valenciana se han publicado en el último lustro de nuestro siglo, escritos que oportunamente iremos citando y comentando a lo largo de este trabajo.

En muchas de las últimas publicaciones sobre pintura valenciana de los siglos XV y XVI se han alcanzado incuestionables progresos, a los que quisiéramos contribuir con nuestro pequeño grano de arena; con nuestras meditadas consideraciones y con nuestro reflexionado punto de vista historiográfico. 


\section{BARTOLOMÉ BERMEJO}

La primera obra a la que deseamos referirnos es la diminuta pero importante Virgen de la Leche de Bartolomé Bermejo (fig. 1), que se conserva en el Museo de Bellas Artes de Valencia (inv. 279). No hace mucho se ha reclamado para esta tabla una adscripción a Pedro Berruguete, ${ }^{1}$ pero nos parece más oportuno retomar la mucho más elaborada autoría de Bermejo. En relación con la cabeza de la Virgen se ha hablado vagamente de un "tono cobrizo" y de unos "párpados pesados" (elementos supuestamente berruguetianos), y se prescinde, en cambio, de un cotejo obvio con la Santa Engracia del Museo Isabella Steward Gardner de Boston, de Bartolomé Bermejo, o, del mismo autor, con el Tríptico de la Virgen de Montserrat (fig. 2) conservado en la catedral italiana de Acqui Terme. Tanto la Virgen como el Niño de la tabla de Valencia evidencian una enorme similitud formal con el citado tríptico, ${ }^{2}$ como lo demuestra, por ejemplo, el rasgado de los ojos de la Virgen, su prominente nariz, las sinuosas -y muy bermejianas- arrugas del cuello, o las respectivas anatomías del Niño Jesús. No nos parece acertado cuestionar lo que a todas luces parece evidente, además de razonado por Young, ${ }^{3}$ Rovera ${ }^{4} \mathrm{y}$ sobre todo Berg-Sobré, ${ }^{5}$ y juzgar, en cambio, que la tabla valenciana "muy poco tiene que ver con la Virgen de Montserrat", o "con otras pinturas de Bermejo". Desenfoque muy difícil de comprender, aunque es cierto que nuestra tabla también es afín a Berruguete. Afinidad que se sabía desde la hipótesis de Tormo planteada en 1932, pero que, precisamente ahora, tras los ajustados estudios de Berg Sobré, ha quedado en eso, en pura afinidad.

La atribución a Bermejo realizada por la historiadora del arte norteamericana es extensa (aportando datos históricos y estilísticos de adulta interpretación), concienzuda y desde luego convincente. Nos parece no faltar a la verdad si insistimos en que la crítica ha aceptado su atribución como poco menos que concluyente, incluso a posteriori de la insatisfactoria atribución

\footnotetext{
${ }^{1}$ Cinco siglos de pintura valenciana. Obras del Museo de Bellas Artes de Valencia, (catálogo de exposición), Madrid, 1996, núm. 4, ficha de F. Benito, p. 30. Tormo la hizo en 1932 de escuela de Ávila, entre García del Barco y Pedro Berruguete, este último con interrogante (TORMO, E.: Valencia. Los museos, Madrid, 1932, 1er. fasc., p. 41, núm. 370). Garín recoge el parecer de Tormo, inclinándose por Berruguete (GARÍN ORTIZ DE TARANCO, F.M.: Catálogo-Guía del Museo Provincial de Bellas Artes de San Carlos, Valencia, 1995, p. 90, núm. 279). Pérez Sánchez de forma muy expeditiva, pensó también en Berruguete (PÉREZ SÁNCHEZ, A. E.: Panorama de la pintura española desde los Reyes Católicos a Goya, Madrid, 1980, pp. 4-5). Todas estas opiniones derivan de la lacónica e insegura apreciación de don Elías Tormo en 1932. En cambio, la opinión que más adelante desarrolló Judith Berg Sobré es, como se verá, mucho más elaborada, precisa y convincente.

${ }^{2}$ Aunque aceptamos que la calidad de la tablita valenciana es más discreta que la del tríptico italiano.

${ }^{3}$ YOUNG, E.: Bartolomé Bermejo. The Great Hispano-Flemish Master, Londres, 1975, p. 80, lám. 46.

${ }^{4}$ ROVERA, G.: "Il pittore Bartolomé Bermejo e i collaboratori Rodrigo de Osona padre e figlio", en Bartolomé Bermejo e il Trittico di Acqui , Acqui Terme, 1987 (pp. 41-88), p. 46.

${ }^{5}$ BERG-SOBRÉ, J.: "Bartolomé Bermejo and Valencia, a Reevaluation", en XXIII Congreso Internacional de Historia del Arte, Granada, 1976, vol. I, pp. 304-308. "La tabla de la Virgen de la Leche de Bartolomé Bermejo en el Museo de Bellas Artes de Valencia y algunas reflexiones sobre su educación artística”, Archivo de Arte Valenciano, 1988, pp. 54-59. "Bartolomé de Cárdenas. Virgen de la Leche", en El Mundo de los Osona, Valencia, 1997, pp. 114-117, núm. 5. "Virgen de la Leche. Bartolomé Bermejo", en Madonnas y vírgenes, s. XIV-XVI, Alicante, 1995, pp. 120-124. Procede reconocer, como advierte Benito, que Berg-Sobré no ha tenido en cuenta las lacónicas opiniones de Tormo y Pérez Sánchez; sí, en cambio, la de Garín, además de aportar que en los archivos fotográficos del Instituto Amatller de Barcelona consta como de Paolo da San Leocadio, y que en las fichas fotográficas de la Universidad de Harvard está clasificada como de autor flamenco del siglo XV.

${ }^{6}$ Cinco siglos... , cit., 1996, núm. 4, p. 30.
} 
a Berruguete.' Por otro lado, de todos es conocido que la historiadora americana ha estudiado, razonado y demostrado cuál es el catálogo más idóneo que a fecha de hoy puede y debe atribuirse a Bermejo. Son casi treinta años dedicados al pormenorizado análisis de la pintura bermejiana, ${ }^{8} \mathrm{y}$ desde luego nadie, que nosotros sepamos, ha cuestionado o cuestiona su estudio. ${ }^{9}$ Recordemos finalmente -y esto para nosotros es muy importante-, que nuestra Virgen de la Leche procede de Valencia (en concreto del Convento de Santo Domingo), ciudad y reino en los que sí trabajó Bermejo, pero nunca Berruguete. Concluimos, por tanto, que la Virgen de la Leche del museo de Valencia es una indiscutible obra de Bartolomé Bermejo, realizada en torno a 1468, fecha en que el pintor cordobés aparece por primera vez documentado en el antiguo Reino de Valencia.

\section{RODRIGO DE OSONA YEL MAESTRO DE ARTÉS}

Oportuna y atractiva nos ha parecido la reflexión establecida"10 sobre el magnífico "Planctus Mariae" o Piedad al pie de la cruz que se conserva en el Museo de Bellas Artes de Valencia (inv. 203), obra que en el mencionado catálogo de $1996^{11}$ se atribuye a Rodrigo de Osona. La verdad es que esta tabla ha sido hasta ahora indistintamente atribuida a Rodrigo de Osona y al llamado Maestro de Artés. En 1908 Tramoyeres pensó en Rodrigo de Osona, ${ }^{12}$ toda vez que indicaba la correcta procedencia de nuestra tabla de la cartuja de Portaceli (Serra, Valencia). Sin embargo, quince años después Tormo ya comenzaba a exponer lo que hasta nuestros días han sido dudas atributivas en torno a esta excelenta tabla de la pintura valenciana. ${ }^{13}$ En 1932 Tormo se inclinó por Rodrigo de Osona, padre, ${ }^{14}$ pero un año después, en lo que sin duda constituye su trabajo más razonado y extenso sobre la pintura de los Osona, no dudó en atribuir nuestra Piedad al entonces llamado Maestro de los Siete Dolores, conocido más adelante como Maestro de Borbotó, quien precisamente está estrechísimamente relacionado con el Maestro de Artés.15 El planteamiento en que Tormo rechaza la autoría de Osona es de una increíble agudeza visual (inadvertida en el estudio de 1996 ), pero es que además, y de forma absolutamente independiente, coincide de lleno con lo que en fecha idéntica (1932), y por caminos diferentes, expuso otro gran historiador de la pintura valenciana, don Leandro de'Saralegui. Nos parece que el planteamiento de don Leandro no tiene desperdicio y nos permitimos por ello traerlo a colación. En un principio Saralegui atribuyó nuestra Piedad a Rodrigo de Osona, con interrogante ${ }^{16}$ pero, y he aquí lo sorprendente, a su lado ilustró dos tablas más (dos desaparecidos calva-

\footnotetext{
${ }^{7}$ MARZAL, M. (ed. a cargo de): Recuperando nuestro patrimonio, Valencia, 1999, p. 17. CHIACCHIO, M. L.: "Bartolomé Bermejo, Virgen de la Leche”, en el seminario Las artes en España entre Gótico y Renacimiento: el papel de Valencia, Valencia, del 5 al 12 de julio de 1999 (inédito).

${ }^{8}$ Todo empezó con una magnífica Tesis Doctoral inédita (existe un ejemplar en la biblioteca del Instituto Amatller de Barcelona); BERG-SOBRÉ, J. : Bartolomé Bermejo, Harvard University, 1969 (inédito).

${ }^{9}$ Véase su último trabajo, Bartolomé de Cárdenas "El Bermejo". Pintor errante en la Corona de Aragón, San Francisco, Londres, Bethesda, 1997. Cfr. nuestra recensión sobre el citado libro; COMPANY, X.: "Judith Berg-Sobré: Bartolomé de Cárdenas El Bermejo", Archivo de Arte Valenciano, 1997, pp. 286-288.

${ }^{10}$ Cinco siglos..., cit., 1996, núm. 5, p. 32.

"Ibidem.

${ }^{12}$ TRAMOYERES, L.: "Los cuatrocentistas valencianos, el Maestro Rodrigo de Osona y su hijo del mismo nombre", Cultura Española , 1908, pp. 139-156.

${ }^{13}$ TORMO, E.: Levante (provincias valencianas y murcianas), Madrid, 1923, p. 148. Aquí ya se habla de "discípulo de Osona (si no es suya)".

${ }^{14}$ TORMO, E.: Valencia. Los Museos, cit., 1932, p. 41, núm. 362.

${ }^{15}$ TORMO, E. : "Rodrigo de Osona, padre e hijo, y su escuela (II)", Archivo Español de Arte y Arqueología, 1933 (pp. 153-210), p. 173, nota 1, y lám. LXXI.

${ }^{16}$ SARALEGUI, L. : "Miscelánea de tablas valencianas", Boletín de la Sociedad Española de Excursiones , 1932 (pp. 50-55), p. 53, lám. VI.
} 
rios de la catedral de Valencia) que atribuyó con el mismo interrogante a Rodrigo de Osona, o a "su escuela" (sic), los cuales, sin ningún género de dudas, pertenecen al Maestro de Artés." Es decir, sin proponérselo de forma directa, Saralegui estaba concluyendo, de un modo muy sagaz, que la Piedad del Museo de Bellas Artes de Valencia es una obra clara del Maestro de Artés, creído entonces -como ahora-, afín o próximo a Rodrigo de Osona.

Sugerimos que el lector observe las figuras 3 y 4 para corroborar lo dicho, y, sobre todo, para comprobar por qué es mucho más sensato atribuir nuestra Piedad al Maestro de Artés que a Rodrigo de Osona. Se explica así, tras todo lo dicho, la lógica conclusión que Post establecía en 1935: "It is not difficult to see an authentic work of the Artés Master in a Pietà of the Provincial Museum, Valencia". ${ }^{18}$ A nuestro juicio, conocer todo este fecundo discurso resulta de suma importancia para descubrir la verdadera trama interna de la pintura valenciana del primer Renacimiento.

¿Quién es, sin embargo, el Maestro de Artés? La mejor respuesta creemos que la tiene Maite Framis, pero no seremos nosotros quienes desvelemos o anticipemos, por ahora, nada de lo que esta rigurosa historiadora del arte prepara como Tesis Doctoral bajo la dirección de uno de los firmantes de este trabajo. Sí se puede apelar, sin embargo, por el momento, a la vieja y conocida propuesta de identificar al Maestro de Artés con el documentado Pere Cabanes, pintor que precisamente podemos relacionar con Rodrigo de Osona. En el mencionado catálogo de 1996 se ha escrito que Pere Cabanes "era ajeno por completo al taller osonesco", ${ }^{9}$ lo que no coadyuva al correcto análisis de la Piedad del museo de Valencia. Negando la relación de Pere Cabanes con Rodrigo de Osona se impide progresar en la correcta atribución de nuestra tabla y, aún más, en una idónea comprensión de la pintura valenciana desarrollada en torno a $1500{ }^{20}$

Hoy se sabe que entre los extremos de 1482 y 1507 Rodrigo de Osona y Pere Cabanes (Maestro de Artés?) trabajan juntos, lo que tal vez constituye una anilla fundamental en el correcto análisis y en la correcta atribución de nuestra Piedad . De hecho, para un Calvario (fig. 4) muy afín a nuestra Piedad, Saralegui escribió en 1932 lo siguiente: "no me sorprendería que esta tabla, procedente de Valencia, fuese del retablo contratado en 1482 por Osona y Pedro Cabanes, con los herederos de Vicente Pedro para el altar mayor de San Francisco". A A lo cual nosotros añadiríamos que idéntico razonamiento podría hacerse de la Piedad que nos ocupa. Es decir, nuestra tabla (y tantas otras tablas de la pintura valenciana de esta época) podría admitir el bastante. usual concurso de dos manos diferentes y a su vez complementarias (en este caso, y de forma hipotética, Rodrigo de Osona y Pere Cabanes; sin olvidar la posibilidad de Francisco de Osona), lo que en verdad justificaría y explicaría las comprensibles vacilaciones atributivas de los mencionados autores, apuntadas también, de antaño, por Carlos Soler d' Hyver, ${ }^{2}$ por Ximo Company, ${ }^{23}$ y por Maite Framis..$^{24}$ Porque, desde luego, cabe admitir

\footnotetext{
${ }^{17}$ Ibid., pp. 51-52, lám. VII y VIII.

${ }^{18}$ POST, Ch.R.: A History of Spanish Painting, vol. VI-I: The Valencian School in the Late Middle Ages and Early Renaissance, Cambridge, Massachusetts, 1935, p. 308.

${ }^{19}$ Cinco siglos... , cit., 1996, p. 32. Se sabe, desde 1913 (TORMO, E.: Jacomart y el arte hispano-flamenco cuatrocentista , Madrid, 1913, p. 120), que en 1482 Rodrigo de Osona y Pere Cabanes eran socios. Cfr. SANCHIS SIVERA, J.: Pintores medievales en Valencia, Valencia, 1930, pp. 194 y 206.

${ }^{20} \mathrm{El} \mathrm{mismo} \mathrm{Benito} \mathrm{ha} \mathrm{dejado} \mathrm{vacío} \mathrm{de} \mathrm{contenido} \mathrm{un} \mathrm{valioso} \mathrm{documento} \mathrm{exhumado} \mathrm{por} \mathrm{don} \mathrm{Vicente} \mathrm{Vallés} \mathrm{Borrás} \mathrm{en}$ el que se verifica de nuevo que todavía en 1507 (o muy poco antes) Rodrigo de Osona y Pere Cabanes trabajaban juntos, en concreto en las pinturas de la predela del retablo mayor de la parroquia de Santo Tomás de Valencia. Cfr. BENITO, F.; GÓMEZ, J.; SAMPER, V.: Los Hernandos. Pintores hispanos dél entorno de Leonardo, Valencia, 1998, p. 267.

${ }^{21}$ SARALEGUI, cit., p. 51.

${ }^{22}$ SOLER D'HYVER, C.: El Siglo XV valenciano, Madrid, 1973, núm. 8, pp. 67-68.

${ }^{23}$ COMPANY, X.: La pintura dels Osona: una cruïlla d'hispanismes, flamenquismes i italianismes, Lleida, 1991, vol. I, pp. 104-109.

${ }^{24}$ FRAMIS, M.: "Taller de los Osona: Piedad al pie de la cruz (Planctus Mariae)", en El mundo de los Osona, Valencia, 1994, pp. 168-171. Véase también COMPANY, X.; FRAMIS, M.: "Mestre d'Artés. Pietat al peu de la creu", en $\mathrm{Ca}$ tálogo de los fondos pictóricos del Museo San Pio V, inédito (Valencia 1995).
} 


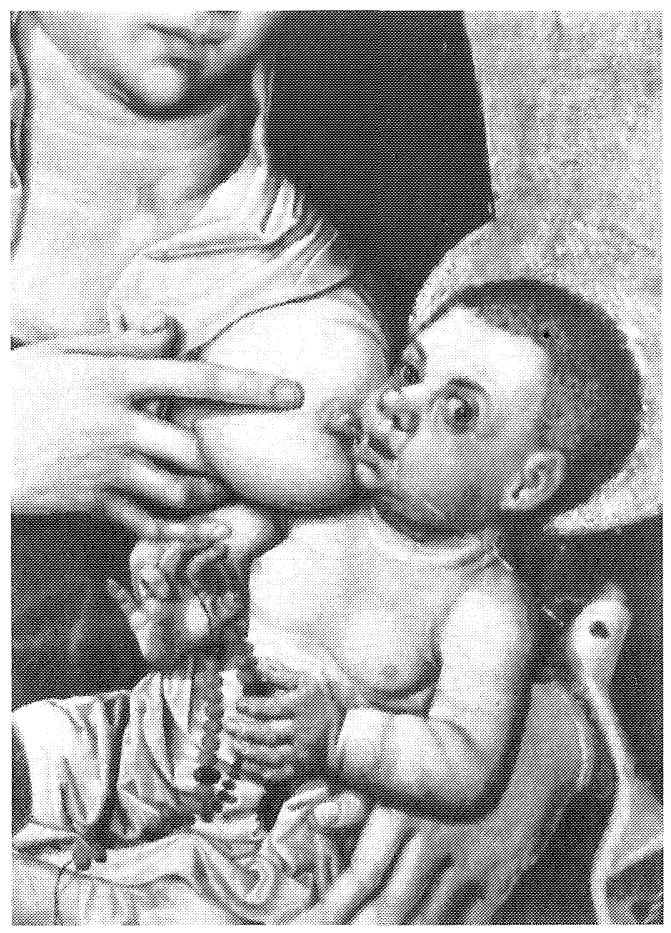

Fig. 1 Bartolomé Bermejo: Virgen de la Leche, detalle del Niño. Valencia, Museo de Bellas Artes; h. $1465-1470$.

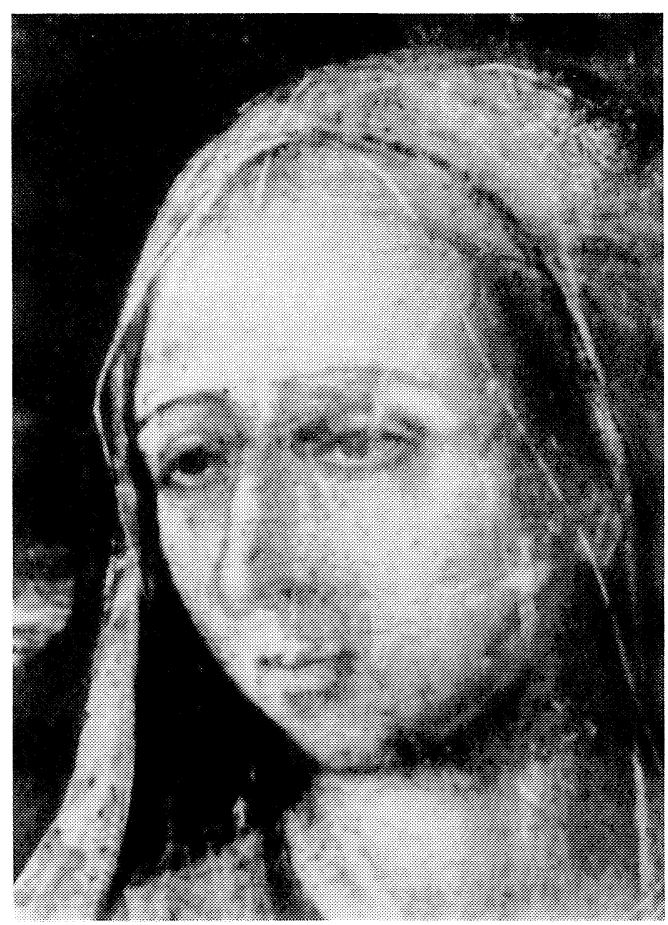

Fig. 3 Maestro de Artés (con posible participación de Rodrigo de Osona): Piedad al pie de la cruz (Planctus Mariae), detalle de María Magdalena. Valencia, Museo de Bellas Artes; h. 1500.

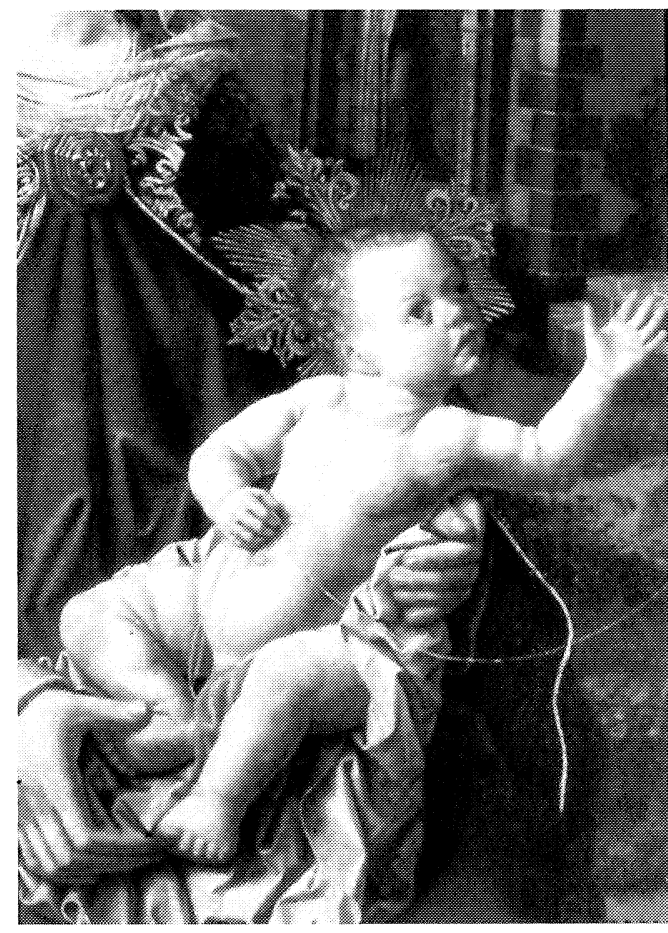

Fig. 2 Bartolomé Bermejo: Tríptico de la Virgen de Montserrat, tabla central, detalle del Niño. Acqui Terme (Italia), Catedral; entre 1481-1485.

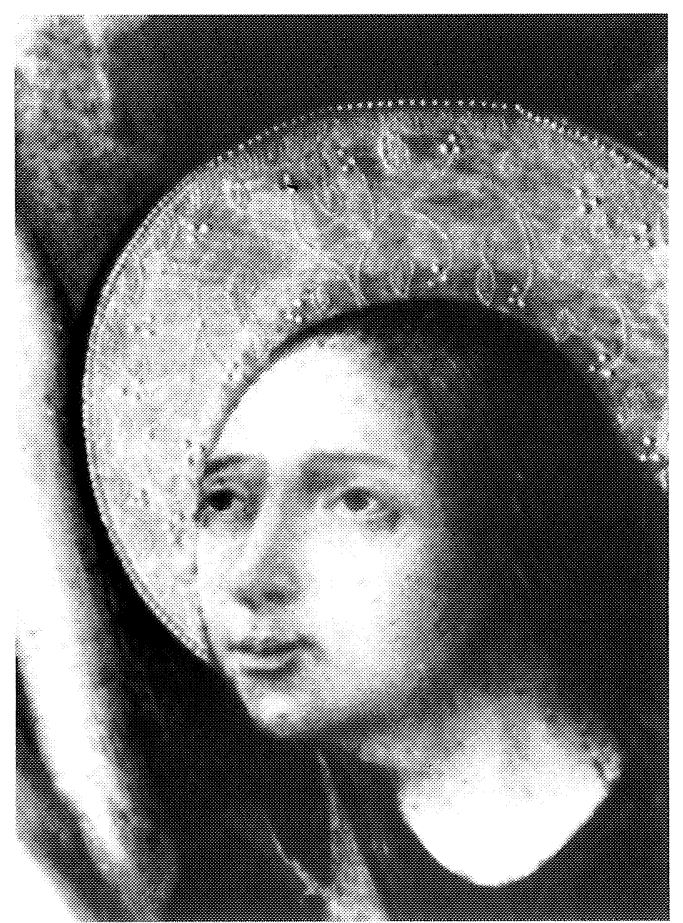

Fig. 4 Maestro de Artés: Calvario, detalle de San Juan. Valencia, Catedral (desaparecido); h. 1500. 
y reconocer que el paisaje de nuestra Piedad podría relacionarse con otros paisajes de Rodrigo de Osona, como sucede, por ejemplo, en el conocido Calvario de la iglesia de San Nicolás de Valencia.. ${ }^{5}$ En efecto, no hay ningún paisaje como éste, tan exquisito y detallista, en toda la producción pictórica del Maestro de Artés. Lo lógico, por tanto, es admitir la hipotética presencia osonesca en el paisaje y tal vez también en la cabeza de la Virgen (con factura afín a las tipologías de Francisco de Osona), lo que explicaría el sentido dicotómico de nuestra tabla. No advertimos, en cambio, como se sugiere en el estudio de 1996, demasiadas relaciones entre la Magdalena de nuestra tabla y la Magdalena que aparece en el Calvario realizado por Rodrigo de Osona en 1476. Precisamente es esta una de las figuras que con más claridad desautoriza la atribución de esta Piedad a Rodrigo de Osona (véanse las figuras 3 y 4 ).

Una provechosa recapitulación de todo lo expuesto hasta ahora nos lleva a la sabida conclusión de que los talleres pictóricos de los siglos XV y XVI eran eso, talleres colectivos, lo que explica y justifica las numerosas dificultades con que nos encontramos los historiadores del arte, a la hora de establecer correctas atribuciones. Tal es así, nuestra dificultad, que a menudo corremos el peligro de querer descender a un absurdo maniqueísmo atributivo. Es decir, a querer reglar las atribuciones de un modo demasiado rígido, demasiado exacto y concluyente. Algo de esto, a nuestro entender, ha ocurrido al plantear el complejo catálogo pictórico de Vicent Macip, al que nos referimos de inmediato.

\section{DE VICENT MACIP A JOAN DE JOANES}

Los historiadores del arte en general, especialmente los que nos venimos ocupando de la pintura gótica y del Renacimiento en Valencia, debemos reconocer como positiva la propuesta de identificación entre el Maestro de Cabanyes ${ }^{26} \mathrm{y}$ el gran pintor español Vicent Macip. ${ }^{27} \mathrm{Se}$ trata de un planteamiento bien elaborado, al menos desde nuestro punto de vista. ${ }^{28}$ Nos parece justo advertir, sin embargo, que dicha identificación maduró hace ya muchos años en la cabeza y en la pluma de don José Albi, ${ }^{29}$ a quien sólo le faltó un pequeño punto de verificación documental. Albi, sin embargo, llegó muy lejos en sus conclusiones de 1979, y justo es que se le reconozca el fructífero mérito de su propuesta. Albi llegó a escribir algo tan fundamental como que el arte del Maestro de Cabanyes y Vicent Macip "Illegan prácticamente a confundirse" . ${ }^{30}$ "Más que una consecuencia -escribe Albi referido a Macip en relación al Maestro de Cabanyes-, es una prolongación de la suya" ${ }^{31}$ En fin, Albi dijo mucho y nos parece del todo justo que desde estas líneas reciba el homenaje y consideración que sin duda merece.

$\mathrm{Y}$ dicho esto, que para nosotros es bastante esencial, quisiéramos expresar nuestro punto de vista sobre las comprensibles reticencias que algunos especialistas han manifestado a la hora de aceptar la ecuación que identifica al Maestro de Cabanyes con Vicent Macip. Nos consta, al menos, que ni Soler d'Hyver, ni M. A. Català, ni Padrón Mérida, entre otros, están de acuerdo con ella. ${ }^{32}$

\footnotetext{
${ }^{25}$ COMPANY, X.: El mundo de los Osona, ca. 1460 - ca. 1540, Valencia, 1994, pp. 100-109.

${ }^{26}$ POST, cit., 1935, VI-II, pp. 395-430.

${ }^{27}$ BENITO, F.: "El maestro de Cabanyes y Vicente Macip. Un solo artista en etapas distintas de su carrera", Archivo Español de Arte, LXVI, núm. 263, 1993, pp. 223-244.

${ }_{28}^{28}$ COMPANY, X.; TOLOSA, L.: "Petjades joanesques a la Safor. Reflexions sobre el codi lingüístic més important de la pintura valenciana del segle XVI”, en Miscel.lània Josep Camarena , Gandía, 1997 (pp. 101-127), p. 103.

${ }^{29}$ ALBI, J.: Joan de Joanes y su círculo artístico, Valencia, 1979, 3 vols.

${ }^{30}$ ALBI, J.: Joan de Joanes (+1579) , Madrid, 1979, pp. 9-10.

${ }^{31}$ ALBI, J.: Joan de Joanes y su círculo artístico, Valencia, 1979, vol. I, p. 221. Idéntico razonamiento puede verse en otro escrito de ALBI, J.: "La huella de los Hernandos en el arte de Vicente Macip y de Joan de Joanes", Archivo de Arte Valenciano, 1979 [pp. 17-32], p. 17.

${ }^{32}$ SOLER D'HYVER, C.; CATALÀ, M. A.: “Maestro de Cabanyes: Predela de las Santas”, en El mundo de los Oso$n a$, Valencia, 1994, p. 178-185. PADRÓN MÉRIDA, A.: "Sebastiano del Piombo y su influjo en España. Precisiones a una exposición", Galería Antiquaria , núm. 127, Madrid, abril 1995, pp. 83-89. Cfr. Company, x.: "Maestro de Cabanyes (Vicent Macip?)", en Elmundo de los Osona, 1994, pp. 267-269.
} 
Los razonamientos pueden hacerse de lo más extensos que uno quiera, pero a nuestro juicio basta con una sola confrontación visual para ahondar en la médula del problema suscitado. Es decir, ¿debe aceptarse la ecuación del Maestro de Cabanyes igual a Vicent Macip?

Proponemos una sencilla y elemental comparación entre la cabeza de Santa Ana (fig. 5) (del catálogo del antiguo Maestro de Cabanyes) ${ }^{33}$ y la cabeza de un San Sebastián del museo valenciano, atribuido a Macip (fig. 6). ${ }^{34}$ La conclusión para nosotros es rotunda, indiscutible, de puro sentido común. Consideramos imposible que ambas obras sean de un sólo y único pintor. Los que hemos visto y estudiado pintura abundante de este período sabemos que en un sólo pintor no acostumbran a producirse metamorfosis tan radicales. Y desde luego nuestro razonamiento (compartido por el de muchos otros especialistas españoles) no puede variar por la endeble teoría de la llegada a Valencia, en 1521, de cuatro tablas de Sebastiano del Piombo que, de forma bastante súbita, debieron suponer una especie de revolución mental en las categorías formales y espirituales de Vicent Macip. ${ }^{35}$ Hace ya muchos ãños que aprendimos de maestros y colegas como don José Rogelio Buendía, don Santiago Alcolea Gil, don Josep Gudiol i Ricard, entre muchos otros, de don José Milicua o del experto profesor italiano Ferdinando Bologna, que en la España de 1500, o en la de 1530, los pintores no acostumbraban a vivir y a experimentar cambios tan radicales.

Dicho de otro modo, y aplicados al tema concreto de nuestro estudio, consideramos que el Vicent Macip de la extendida y arraigada fase.del Maestro Cabanyes (h.1500-1525) no pudo desembocar, por sí mismo, en exclusiva, y de forma tan súbita, en lo que hasta ahora se ha tenido como fase última, en solitario, de Vicent Macip. Y volvemos a las imágenes para corroborar lo dicho. En la figura 7, por ejemplo, vemos un detalle de la Virgen, Santa Ana y el Niño del Museo de Bellas Artes de Valencia, obra de Vicent Macip (fase Maestro de Cabanyes) ${ }^{36}$ En cambio, en la figura 8 aparece el mismo tema (Annaselbsdritt o Ana trina) conservado en una colección particular de Madrid, atribuida a Vicent Macip. ${ }^{37}$ ¿Es posible aceptar una misma paternidad para ambas tablas? Desde luego que no. Parece prácticamente imposible. Honestamente nos parece que se trata de una atribución a todas luces insostenible. Y huelga hacer cualquier tipo de comparación formal; no procede; son incuestionablemente diferentes, por más que apelemos a la socorrida excusa de las diferencias cronológicas, que las hay, por supuesto.

¿Qué ocurre? ¿Dónde podría residir la frágil consistencia del discurso que identifica al Maestro de Cabanyes con Vicent Macip? Porque, desde luego, el macro-Macip que surge de esta ecuación nos parece francamente inaceptable. La propuesta tiene sus aspectos positivos, pero peca a su vez, a nuestro juicio, de insuficiente. ¿Cómo es posible que a los cincuenta años de edad un

\footnotetext{
${ }^{33}$ Figura de la llamada Predela de las Santas conservada en el Museo de Bellas Artes de Valencia. Véase una óptima reproducción en COMPANY, X.: Museo de Bellas Artes San Pío V. Obras Maestras, Valencia, 1995, p. 52.

${ }^{34}$ BENITO, F.; GALDÓN, J. L.: Vicente Macip (h.1475-1550), Valencia, 1997, p. 145. Cfr. la imagen de COMPANY, cit., 1995, p. 56.

${ }^{35}$ BENITO, cit., 1993, p. 223. Y del mismo autor "Sobre la influencia de Sebastiano del Piombo en España", Boletín del Museo del Prado, 1998, pp.5-29; "Sebastiano del Piombo y España", en catálogo de Sebastiano del Piombo y Espa$\tilde{n} a$, Madrid, 1995, pp. 41-79. Con lo dicho no negamos que las tablas de Piombo no incidieran en la pintura valenciana del siglo XVI. La influencia de Sebastiano del Piombo en Macip ya fue advertida a principios de siglo por Justi y Mayer; véase ALBI, cit., 1979, vol. I, p. 90 y 238. Véase también LÓPEZ-REY, J.: "Vicente Macip, Sebastiano del Piombo et l'esperit tridentin", Gazette des Beaux-Arts, tomo LXXVIII, diciembre, 1971, pp. 343-354.

${ }^{36}$ BENITO-GALDÓN, cit., 1997, pp.62-63.

${ }^{37}$ Ibid., p. 148. Dimos a conocer esta tabla en 1993 (del mismo conjunto que el San Sebastián, fig. 6) y propusimos la lógica participación de Joanes (COMPANY, X.: "Vicente Macip: La Virgen y el Niño con Santa Ana", en De la Edad Media al Romanticismo , catálogo de Caylus, 1993, pp. 54-59; "Santa Ana, la Virgen y el Niño: nueva obra de Vicente Macip”, en Primer Congreso de Historia del Arte Valenciano, Valencia, 1993, pp. 373-375). Hoy vemos todavía más lógica la mano de Joanes, especialmente porque nos estamos refiriendo a una tardía cronología de hacia 1540; por estas fechas, como se verá más adelante, Vicent Macip ya está inactivo. Benito y Galdón, en cambio, incomprensiblemente, han escrito que "nada concreto en ella permite señalar el pincel de su hijo Joan de Joanes" (BENITO-GALDÓN, cit.,1997, p.148).
} 


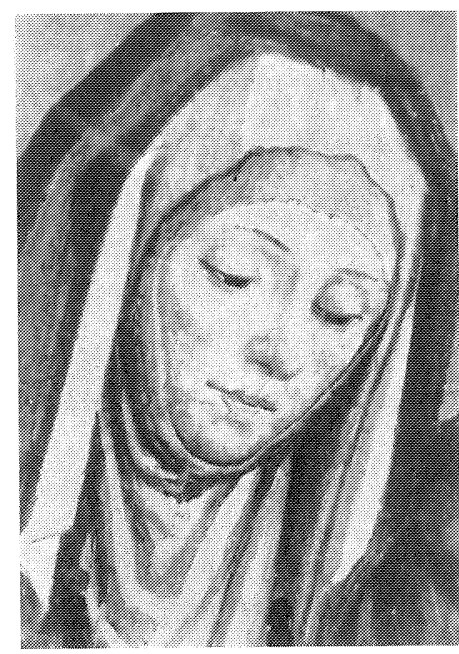

Fig. 5 Vicent Macip (fase Maestro de Cabanyes): Predela de las Santas, detalle de Santa Ana. Valencia, Museo de Bellas Artes; h. 1500-1515.

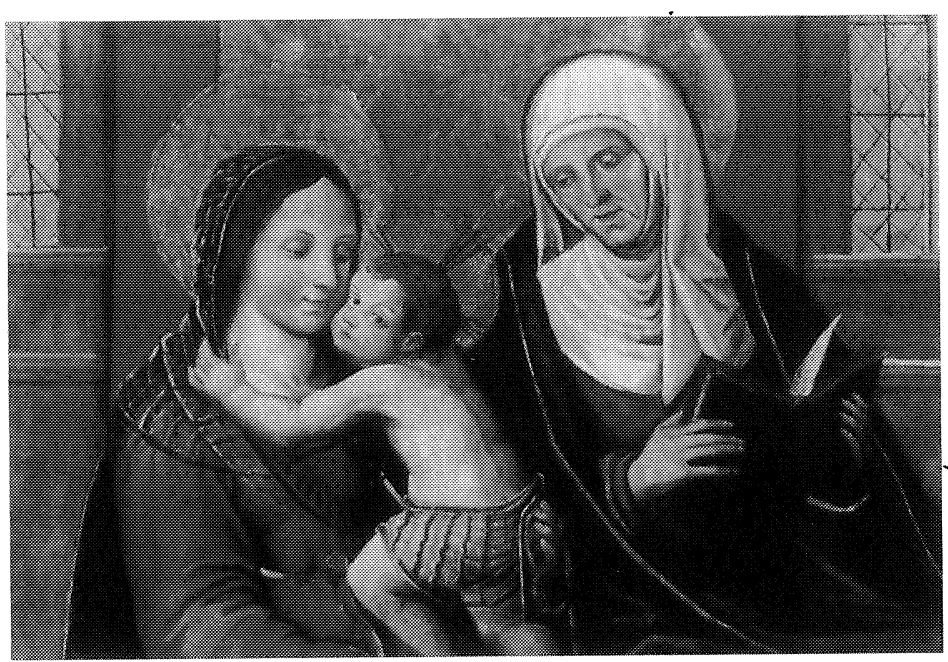

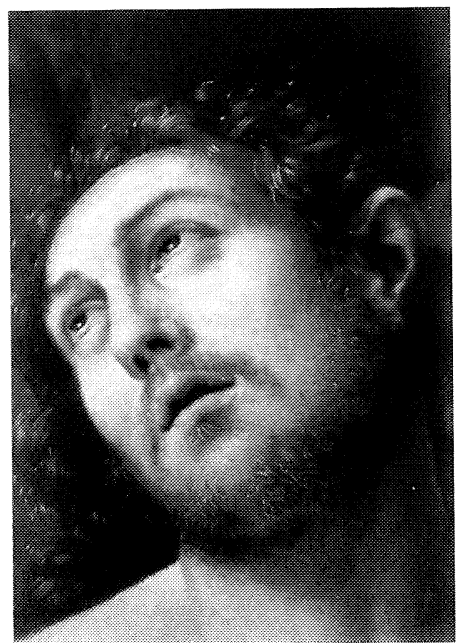

Fig. 6 Joan de Joanes: San Sebastián, detalle. Valencia, Museo de Bellas Artes; h. 1540-1545.

Fig. 7 Vicent Macip (fase Maestro de Cabanyes): Santa Ana, la Virgen y el Niño, detalle. Valencia, Museo de Bellas Artes; h. 1510-1520.

Fig. 8. Joan de Joanes: Santa Ana la Virgen y el Niño (del mismo conjunto que la fig. 6), detalle. Madrid, colección particular; $h$. 1540-1545.

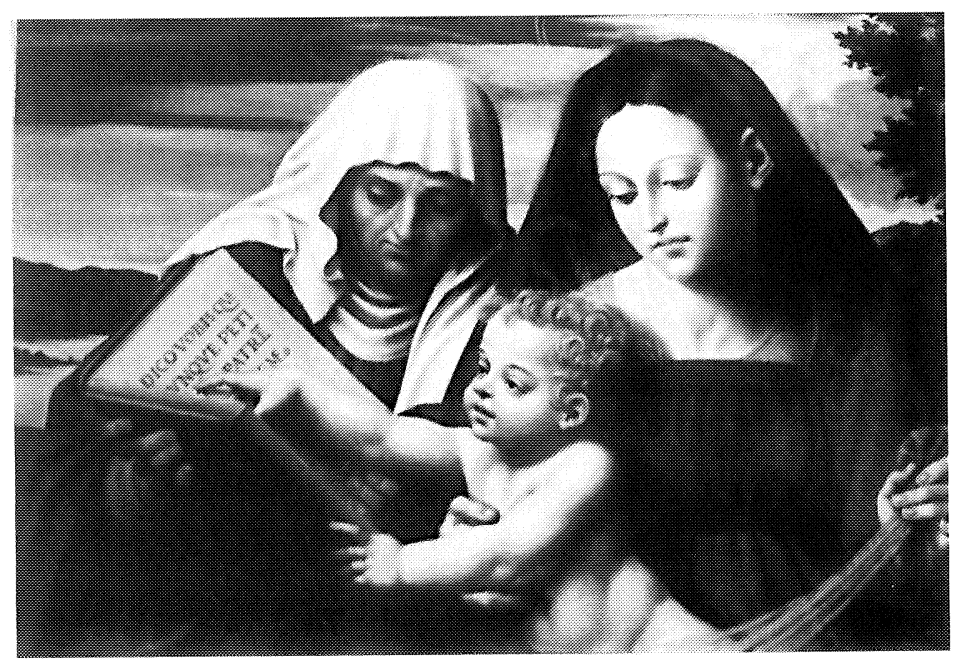


pintor invariablemente coherente con sus esquemas y estilemas tradicionales sufra, de repente, un cambio tan radical? $?^{38}$ Evidentemente o nos falta una anilla por la parte cronológica inferior (es decir, en el pintor que hasta ahora entendíamos como el Maestro de Cabanyes), o algo sucede en la franja cronológica superior de Vicent Macip. De momento, lo más sencillo, lo que parece más lógico y sensato, lo que documental y formalmente puede probarse sin temor a equívocos, es que Joan de Joanes, el hijo de Vicent Macip, interviene, de forma mucho más notoria de lo hasta ahora pensado, en la última fase de su padre. ${ }^{3{ }^{3}}$ En cualquier caso, lo que invariablemente debe desestimarse es el abultado catálogo que se pretende atribuir a un sólo Vicent Macip. En un mismo paquete aparecen obras de clarísimo taller, ${ }^{40}$ derivadas o afines a lo hasta ahora considerado como del Maestro de Cabanyes (por ejemplo el Retablo de la Dormición de María ) ${ }^{41}$ otras son de mano ajena (aunque afín) al Maestro de Cabanyes (por ejemplo el Calvario de la Redención de la colección Orts-Bosch de Valencia), ${ }_{, 2}$ mientras que otras son a nuestro juicio mayoritariamente de Joanes, como sucede, por ejemplo, entre otros casos, con el famoso Bautismo de Jesús de la catedral de Valencia (fig. 9), ${ }^{43}$ o con la citada tabla de la Virgen, Santa Ana y el Niño de una colección particular madrileña (fig. 8). Nos parece que es un buen momento para establecer que la factura del Bautismo de la catedral valenciana, por ejemplo, difiere enormemente de la que encontramos en la ya citada predela de las santas, obra de Vicent Macip en su fase de Maestro de Cabanyes (fig.5). Insistimos, pues, en que cabalmente no se puede admitir una única autoría para ambas tablas (figs. 9 y 5). Nos parece un planteamiento atributivo insostenible.

De todos modos no es nuestra intención repasar aquí, una por una, todas las obras que se atribuyen a Macip en el catálogo de 1997. Tratamos de constatar, simplemente, que de ningún modo Vicent Macip, en solitario, pudo realizar toda la obra que se le atribuye. Y retomamos con ello lo dicho más arriba al referirnos a la doble autoría de Rodrigo de Osona y el Maestro de Artés (Pere Cabanes?), en la Piedad citada del Museo de Valencia, es decir, a la necesidad que tenemos los historiadores del arte de incorporar en nuestras categorías de pensamiento lo que nosotros hemos venido llamando períodos o etapas bisagra. ${ }^{4}$ Las tuvieron Rodrigo de Osona y su hijo Francisco,

\footnotetext{
${ }^{38}$ De acuerdo con Albi, Macip hubiera podido nacer hacia 1475 (o tal vez con anterioridad), con lo que al realizar el retablo de Segorbe (pagos desde el 25 de noviembre de 1529) contaba 54 años. Cuando llegaron a Valencia las tablas de Piombo contaba unos 46 años de edat. Cfr. ALBI, cit., 1979, vol. I, pp. 18-19. Según Post, Macip pudo nacer en 1470, lo que aún refuerza más nuestro planteamiento (POST, Ch. R.: A History of Spanish Painting, Vol. XI: The Valencian School in the Early Renaissance, Cambridge, Massachusetts, 1953, p. 53). Benito y Galdón también consideran extraño un cambio estilístico en Macip a los casi cincuenta años; pero a la postre acaban aceptándolo plenamente (BENITO-GALDÓN, cit., 1997, p. 28).

${ }^{39}$ Los documentos escritos sitúan a Joanes en Segorbe en 1531 (PÉREZ MARTÍN, J.: "Pintores valencianos medievales y modernos. Addenda", Archivo Español de Arte y Arqueología, núm. 35, 1935, p. 302); los documentos plásticos, en concreto las obras del retablo mayor de la catedral de Segorbe, corroboran la presencia de Joanes en 1531, y aún quizá desde 1529. Su mano está en Segorbe, junto a su padre, de forma aparentemente subrepticia, pero a su vez de un modo real e incontrovertible. Así lo entendió también, hace ya muchos años, el máximo especialista en España de Vicent Macip y Joan de Joanes, el historiador José Albi, quien ya vio la mano de Joanes en algunos paneles de Segorbe; ALBI, cit., 1979, I, pp. 61-63. Véase del mismo autor "Vicente Macip-Joan de Joanes", en Historia del Arte Valenciano, Valencia, 1987, vol. III (pp. 241-280), p. 250.

${ }^{40}$ Benito y Galdón reconocen que en la España del tiempo de Macip los artistas eran cabezas de un taller que operaba con colaboradores (conclusión muy acertada), pero a la postre acaban sin hacer demasiadas distinciones entre el maestro y el taller (BENITO-GALDÓN, cit., 1997, p. 20).

${ }^{41}$ BENITO-GALDÓN, cit., 1997, núm.2, pp. 40-41. Subastado por Sotheby's en Madrid el 20 de noviembre de 1994.

${ }^{42}$ Ibid., núm. 21, pp.76-77. A su lado ilustran un Calvario de Paolo da San Leocadio que según los mencionados autores se conserva en el Monasterio de Santa Clara de Gandía. Nunca estuvo allí y se perdió (de la Colegiata de Gandía) en 1936.

${ }^{43}$ Ibid., núm. 54, pp. 132-133. Albi hace un excelente recuento de todo lo dicho sobre esta espléndida obra y no duda en concluir que "dicha tabla fue pintada, en íntima colaboración, por Macip el Viejo y por su hijo Joanes" (ALBI, cit., 1979, vol. I, p. 77). Por otro lado, y como se verá más adelante, esta tabla fue realizada en 1535, fecha en que Joanes (y no su padre Vicent Macip) ejerce la dirección del taller de los Macip.

${ }^{44}$ COMPANY-TOLOSA, cit., 1997, pp. 105-106.
} 
tal vez también, con toda probabilidad Rodrigo de Osona y Pere Cabanes, sin duda Paolo de San Leocadio y su hijo Felipe Pablo de San Leocadio, y por supuesto, entre otros muchos, Fernando Yáñez de la Almedina y Fernando Llanos. Aquí reside, a nuestro juicio, una ajustada clave interpretativa de la verdadera dimensión de Vicent Macip, padre de Joan de Joanes.

En relación a Vicent Macip hubo un tiempo en que la crítica insistió en su hipotético viaje a Italia, ${ }^{45}$ para después cambiar de opinión, de forma súbita, ${ }^{46}$ considerando que con Paolo de San Leocadio, los Hernandos y sobre todo Sebastiano del Piombo, era más que suficiente para desarrollar un giro filoitaliano de poco menos que de $180^{\circ}$. Se aboga, por tanto, por una especie de cambio endógeno en Macip, olvidándose por completo (o casi) ${ }^{47}$ de lo que en realidad pudo suponer la decisiva influencia exógena de Joan de Joanes en las producciones del viejo Macip. En Segorbe probablemente Joanes ya contaría con más de veinte años (hoy se cre que éste pudo nacer en torno a $1500 \mathrm{o}$ tal vez antes) y por supuesto con una altísima personalidad pictórica. Conocería, por supuesto, las obras de Sebastiano del Piombo en Valencia, y creemos que bastante también las de Rafael y otros pintores toscanos, difundidas por toda Europa a través de numerosos dibujos y estampas. Albi ha señalado la enorme importancia de Rafael en los modos y repertorios pictóricos de Macip y Joanes ${ }^{48}$ especialmente a partir de 1530, precisamente una fecha en la que el joven Joanes irrumpía con fuerza en el taller paterno de Vicent Macip.

De todos modos, existen otros aspectos, perfectamente documentados, que refuerzan nuestra propuesta de considerar la presencia de Joanes en algunas obras que hasta ahora habíamos tenido como de Vicent Macip en solitario.

El historiador Vicente Vallés descubrió hace unos años un dato documental de la máxima importancia, pues en él se verificaba que ya en 1534 Joanes contrataba pintura junto -y por delantede su padre en calidad de maestro reconocido y de honorable ." Lo hizo para el Retablo de San Eloy que estuvo en la parroquia de Santa Catalina, en Valencia, y la verdad es que el contenido de su primera capitulación es de capital importancia para conocer la relevante personalidad de Joan de Joanes. Lo que se dice en este contrato refuerza mucho todo lo que aquí se está tratando de establecer. Es decir, si Joanes aparece como un maestro inequívocamente consumado en el citado contrato de 1534 , todo parece indicar que este prestigio no lo habría podido obtener de la noche a la mañana. Mucho antes, en Segorbe desde luego, ya debería haber pintado abundantemente y bien, pues en el citado documento de 1534 Joanes aparece muy por encima -en cuanto a responsabilidad y categoría artística- de su padre Vicent Macip. Se dice en el primer capítulo del mencionado contrato de 1534, que las pinturas del retablo de San Eloy serán pintadas en exclusiva ${ }^{50}$ por Joan de Joanes, sin ayuda de ninguna otra mano: "que lo dit retaule (...) sia tot pintat de mà del dit

${ }^{45}$ BENITO, F.: "Vicent Macip i Joan de Joanes: semblances i diferències d'un estil pictòric semblant”, Debats, núm. 1, Valencia,1982, pp.41-43. "La pintura durant els segles XVI i XVII", en Història de l'Art al País Valencià , Valencia, 1988 (pp. 61-103), p. 70. Según Albi se hace imprescindible un viaje de Macip a Italia, viaje que pudo darse -según Albi- hacia 1512 (ALBI, cit., 1987, p. 253). Así lo cree también PÉREZ SÁNCHEZ, A. E.: "Juan de Juanes en su centenario", Archivo de Arte Valenciano, 1979, pp. 5-16.

${ }^{46}$ BENITO, cit., 1993, p. 225.

${ }^{47}$ BENITO-GALDÓN, cit., 1997, p. 30.

${ }^{48}$ ALBI, cit., 1975, vol. I, pp. 246-253.

${ }^{49}$ BENITO, F.; VALLÉS, V.: "Nuevas noticias de Vicente Macip y Joan de Joanes", Archivo Español de Arte, LXIV, núm. 255, 1991, pp. 353-361. Cfr. ALBI, cit., 1979, vol. I, p. 17; CAMÓN AZNAR, J.: La pintura española del siglo XVI, Madrid, 1970, p. 86. Con bastante anterioridad el Retablo de San Eloy fue dado a conocer por RODRÍGUEZ-RODA, F. R.: "Los retablos de la Capilla del Gremio de los Plateros de Valencia", Saitabi, 14, diciembre 1944, pp. 327-344. La temprana fecha de 1534 nos hace pensar en un nacimiento de Joanes en torno a 1500. Desde luego es muy probable que hubiera nacido antes de 1510, fecha propuesta por Albi. Benito-Vallés también creen que Joanes debió nacer antes de 1510.

${ }^{50}$ El subrayado es nuestro. 
En Joan Macip, e no de alguna altra persona". ${ }^{.1}$ A su padre, al gran Vicent Macip, sólo le es permitido intervenir en el dorado del mencionado retablo, y siempre al lado, y por detrás, de su hijo Joan, verdadero director y responsable del taller de los Macip, ya en 1534: "que lo dit retaule [se dice en el contrato] haja de esser daurat per lo dit En Joan Macip e pare de aquell...." ${ }^{22}$ La verdad es que se trata de algo tan contundente, tan diáfano y elocuente, que no puede pasarnos desapercibido. El profesor Benito tuvo en sus manos la primicia del valioso documento de 1534 descubierto por Vallés. Sin embargo, en ningún momento se alcanzó a vislumbrar su verdadero significado.

Nos encontramos, nada más y nada menos, con que tan solo tres años después de las pinturas de Segorbe, Joanes ya ha suplantado por completo el antiguo protagonismo de su padre. Algo que, de haberlo sopesado bien la crítica joanesca de hace unos años, hubiera conllevado una obvia renovación en los planteamientos historiográficos hasta entonces realizados..$^{53}$

Queremos decir, que hasta ahora, mientras creíamos que el Maestro de Cabanyes era diferente de Vicent Macip, podía aceptarse una evolución del Macip de Segorbe, al Macip del Bautismo de la catedral de Valencia (fig. 9), y de éste, por ejemplo, al San Sebastián del Museo de Bellas Artes de Valencia (fig. 6), o a la preciosa tabla de la Virgen, Santa Ana y el Ni$\tilde{n} o$ de una colección particular (fig. 8). Ahora, en cambio, tras proponer Benito que Macip podría no ser otro que el sosegado y bastante invariable Maestro de Cabanyes, nos resulta poco menos que imposible admitir una (r)evolución tan súbita en las categorías formales de aquel viejo Macip. Y volvemos a insistir en que eso no pudo darse a los más de 50 años de edad de Vicent Macip, porque hasta entonces (h.1529), su producción fue invariablemente afín y coherente con la larga y extendida producción del Maestro de Cabanyes. Son demasiados años y demasiadas obras, siempre con un semejante repertorio de estilemas formales (aunque, evidentemente, con lógicas y ligeras variantes plásticas y compositivas), como para creer que aquel maestro acomodado y aceptado por una abundante clientela valenciana, pudiera optar por una súbita (r)evolución. Máxime cuando se da la curiosa coincidencia de que cuando Macip, después de tantos años de invariable estandarización de arquetipos formales, se propone hacer el cambio, lo hace en presencia y en plena actividad de su hijo Joan de Joanes.

¿No son demasiadas coincidencias? ¿Por qué cuando Joanes aparece en escena se produce la mutación de Macip? En cambio, ¿por qué Vicent Macip no experimentó mutación alguna significativa en sus primeros 30 años de actividad? ¿Quién es el que en realidad aporta más novedades a aquel consolidado taller, Macip o Joanes? Macip tenía en Segorbe poco más de 50 años y nunca hasta entonces dio visos de mutaciones radicales, ni siquiera significativas. Siempre estuvo acomodado a los bastante invariables y tradicionales estilemas del Maestro de Cabanyes. ¿No sería, por tanto, Joanes, con tal vez más de 25 años, quien verdaderamente insuflaría un nuevo espíritu en el código visual y formal del viejo Macip?

A nuestro juicio estamos en un momento privilegiadamente óptimo para reordenar el esquema interpretativo de la pintura de los Macips. Entendemos que de Vicent Macip en solitario sólo po-

\footnotetext{
${ }^{51}$ BENITO-VALLÉS, cit., 1991, p. 358. La traducción no ofrece dudas: "que el mencionado retablo (...) sea pintado todo de mano del mencionado don Joan Macip [Joan de Joanes], y no por alguna otra persona [incluido su padre Vicent Macip]".

${ }^{52}$ Ibidem.

${ }^{53}$ De hecho, la única obra que se ha conservado del retablo de la parroquia de Santa Catalina de Valencia es una Consagración de San Eloy como obispo de Noyon (Museo de Tucson, Arizona) atribuida en su tiempo (1968), con la lógica de entonces, a Vicent Macip (SOLER D'HYVER, C.: “Un cuadro de Vicente Macip atribuido a Lorenzo Lotto”, Archivo de Arte Valenciano,1968, pp. 99-103). A la postre se trata de una obra que, de no ser por la concluyente documentación publicada por Benito-Vallés en 1991, admitiría la lógica y tradicional participación de Macip. Sin embargo, el contenido del documento de 1534 no presta a equívocos. Por esa fecha, fecha también -no lo olvidemos- del Bautismo de la catedral de Valencia (doc. 1535, fig. 9), el gran artífice del taller de los Macip ya no es el viejo Macip sino su hijo Joan de Joanes.

${ }^{54}$ También nosotros -como prácticamente la mayoría de los historiadores que se han ocupado de los Macip-, llegamos a pensar de otro modo, aunque ahora confesamos y admitimos, tras conocer el documento de 1534, nuestro desenfoque. Véase COMPANY, X.: La pintura del Renaixement (al País Valencià), Valencia, 1987, pp. 55-74.
} 
dría existir la antigua producción del Maestro de Cabanyes (caso de aceptarse la pretendida identificación entre ambos pintores), mientras que el salto cualitativo que se da a partir del retablo de Segorbe se produce por obra y gracia de ese gran renovador que fue Joanes ${ }^{5 s}$, si bien, en la fase de Segorbe, Joanes todavía estuvo marcadamente supeditado a los esquemas y a las enseñanzas formales de su padre Macip. Ambos trabajaron en aquel grandioso retablo, y desde ese preciso momento (h. 1529) Joanes será el gran protagonista, el gran artífice y el incuestionable renovador del hasta entonces tradicional obrador de los Macip. Así las cosas, nos parece de sentido común atribuir mucho más a Joanes que a Macip, todo lo contratado y ejecutado por los Macip, a partir de 1530, como ocurre, por ejemplo, en el Bautismo de la catedral de Valencia, obra de 1535 (fig. 9)..5

Volvemos, de todos modos, al citado retablo de San Eloy para remarcar que en el largo y minucioso texto de su contrato se insiste una y otra vez (hasta en once ocasiones) en que el gran protagonista, el gran maestro y el gran pintor del taller de los Macip, a fecha 20 de junio de 1534, no es Vicent, sino su hijo Joan. En el contrato aparece muy claro y de forma inequívoca: "que lo dit retaule sia pintat de mà del dit en Joan Macip, e no de altra persona", ${ }^{, 7}$ es decir, sólo por Joan de Joanes, sin ayuda de nadie más; ni siquiera de su padre, quien automáticamente pasa a un segundo lugar.

Por tanto, y es aquí donde los críticos e historiadores del arte debemos detenernos con un alto espíritu reflexivo e interpretativo, Joan de Joanes debió tomar el relevo de su padre Vicent Macip muy a principios de la década de los treinta, con todo lo que esto significa en el desarrollo e interpretación de la pintura ėmanada del taller de los Macip a partir de dicha fecha. ${ }^{. s}$ En 1531 Joanes ya cobraba diez ducados a cuenta del retablo de la catedral de Segorbe, ${ }^{, 9}$ lo que certifica sin lugar a equívocos su presencia e intervención en el mencionado conjunto pictórico. Pero es que procede recordar, además, que desde 1531, fecha en que Joanes aparece documentado al lado de su padre, y hasta el 27 de diciembre de 1545 en que éste redacta su testamento, el viejo Macip sólo aparece en solitario, sin su hijo, en dos desdibujadas ocasiones; en concreto el 13 de enero de 1533 (es decir, todavía antes del contrato del retablo de San Eloy) cuando cobra dos libras, cuatro sueldos y ocho dineros, "per rahó de pintar lo retaule de l'Àngel Custodi per al portal de la Mar"; ${ }^{\text {;0 }} \mathrm{y}$ en 1535-1536 cuando un "mestre Vicent, pintor" (sin especificar el apellido), cobra seis sueldos "per pintar de vert les croces de Sent Loís"; una noticia nimia, aunque ve ahora la luz, por primera vez, que nos habla de un pintor que apenas se ocupa de aspectos muy domésticos y secundariōs relacionados con la catedral de Valencia. ${ }^{61}$ En ningún otro trabajo, en ningún otro contrato, aparece sin su hijo Joan de Joanes, quien de forma progresiva va asumiendo las responsabilidades tanto internas como de imagen formal externa de aquel taller, como lo demuestra, por ejemplo, el hecho de que en la tacha real de 1542 el único Macip que aparece en la nómina de los pintores valencianos contribu-

\footnotetext{
${ }^{55}$ Cabeza de serie del taller de los Macip a partir, al menos, de 1534.

${ }^{56}$ Como ya se ha dicho, Albi ya advirtió en 1979 que en el Bautismo de la catedral de Valencia trabajó Joanes (ALBI, cit., 1979, vol. I, p. 77).

${ }^{57}$ Ibid., p. 358.

${ }^{58}$ Así lo pusimos de manifiesto en 1997, insistiendo en que Joan de Joanes debió adquirir su prestigio y reconocimiento en las pinturas del retablo mayor de la catedral de Segorbe, junto a su padre Vicent Macip; véase COMPANYTOLOSA, cit., 1997, pp. 104-105.

${ }^{59}$ PÉREZ MARTÍN, cit., 1935, p. 302.

${ }^{60}$ SANCHIS SIVERA, cit., 1930, p. 233-234. Dicho documento ha sido posteriormente localizado y transcrito en su totalidad por quienes suscriben este trabajo; dice así: "Ítem doní e paguí a-N Vicent Macip, pintor, dos lliures quatre sous huyt diners per rahó de pintar lo retaule de l'Àngel Custodi per al portal de la Mar, les quals li he donat en virtut de la provisió en ans feta sitiada. Ha-n'hi àpoca rebuda per mi dit notari dit dia LIIII ss. VIII" (Arxiu Municipal de València, Sotsobreria de Murs $i$ Valls, 112 f. 199v.). Nos asiste la convicción, sin embargo, de que incluso en este Retablo del Ángel Custodio Joanes pudo estar presente a la hora de su real ejecución formal. ¿Acaso no inspiraría este retablo el posterior Ángel Custodio de la catedral de Valencia (h. 1555-1560), de incontrovertible mano joanesca? Véase SOLER D'HYVER, C.: Joan de Joanes (+1579) , Madrid, 1979, núm. 38, p. 64; también en ALBI, cit., 1979, vol. II, pp. 23-26.

${ }^{61}$ Archivo de la Catedral de Valencia, Libro de Obra , núm. 1489, f. 28 v.
} 
yentes, con 10 sueldos, es Joan de Joanes. ${ }^{22}$ A todo ello habría que añadir la parquedad de referencias documentales relacionadas con Vicent Macip, además de la curiosa noticia que Olimpia Arozena publicó en 1931 según la cual el viejo Macip otorgó un primer testamento ante el notario Joan Guimerà en $1541 .{ }^{{ }^{63}}$ Quiere ello decir que todavía antes de la conocida fecha de 1545, cuando Macip estaba en "edat de senectut" (es decir, incapacitado y rayando o tal vez sobrepasando los setenta años), éste ya había prácticamente abandonado el ejercicio de la pintura.

Sólo así, desde la constatación de un Joan de Joanes pictóricamente emancipado desde al menos 1531, pueden explicarse las anomalías y las contradicciones que muchos historiadores detectaron en la magna exposición de Vicent Macip celebrada en el Museo de Bellas Artes de Valencia en 1997. Fue un acontecimiento de primera magnitud, con labores de restauración y de acopio de obras verdaderamente irrepetible, pero la mayor parte de los especialistas que la visitaron salieron con la lúcida e inequívoca convicción de estar asistiendo, al menos, a dos exposiciones diferentes, precisamente desarrolladas en dos salas distintas y perfectamente diferenciadas. En una se veía claramente la producción pictórica de Vicent Macip (fase Maestro de Cabanyes), aproximadamente desarrollada entrè 1500 y 1529. En otra contemplábamos un mundo pictórico incuestionablemente diferente. Se veía otra mano rectora. Se observaba una sustanciosa mutación formal que sólo podía explicarse por algún factor exógeno a la propia evolución interna de Vicent Macip. Y por supuesto, el pretendido e hipotético poder transformador de Sebastiano del Piombo, en absoluto no resolvía ni podía explicar todos los interrogantes. El viejo Macip, en solitario y en exclusiva, no hubiera desembocado jamás en las grandiosas formas del retablo de Segorbe y en las que le sucedieron. Con sólo Piombo resulta inexplicable una tal (r)evolución. Hacía falta algo más. A nuestro juicio los cambios se producían por la progresiva aparición de la inequívoca mano de Joan de Joanes en diversas tablas del retablo de la catedral de Segorbe. En cambio, en no pocas tablas posteriores a la cronología de Segorbe (h. 15291532), como por ejemplo en la citada Santa Ana, la Virgen y el Niño (fig. 8), se observa con facilidad que la presencia de Joanes es ya abrumadora, contundente y absolutamente determinante. ${ }^{64}$

No nos parece que sea este el lugar oportuno para emitir juicios atributivos sobre las 68 obras del último catálogo dedicado a Vicent Macip (muchas de ellas absolutamente correctas), pero a título meramente orientativo sugerimos que todo buen historiador contemple con ojos cautos, serenos y neutros, algunas partes (cabezas, manos, constituciones anatómicas, arquitecturas y paisajes) $)^{\epsilon}$ del retablo de Segorbe. Veremos a Vicent Macip, es cierto, indiscutible, pero observaremos también, de modo elocuente, la presencia de otro pintor; de Joanes. Veremos préstamos tomados de Piombo (a través de grabados o quizá por medio de las tablas que el diplomático Jerónimo Vich

\footnotetext{
${ }^{62}$ Arxiu Municipal de València, Tacha Real, K3-4. Noticia documental dada a conocer por ALBI, cit., 1979, vol.I, p. 330. Cfr. FALOMIR, M.: La pintura y los pintores en la Valencia del Renacimiento (1472-1620), Valencia, 1994, p. 99.

${ }^{63}$ AROZENA, O.: "El pintor Vicente Macip, padre de Joan de Joanes", Anales de la Universidad de Valencia, año XI, cuaderno 83, 1931 (pp.98-121), p. 99. Cabe advertir que ni Albi ni nosotros hemos dado con el protocolo de Joan Guimerà, con fecha de 1541.

${ }^{64}$ Incluso proponemos que se someta a consideración la autoría del Cristo a la columna de Alba de Tormes (Salamanca). Se habla de Macip en solitario (BENITO-GALDÓN, cit., 1997, núm. 55, pp. 136-137), pero una vez más se trata de una obra absolutamente al margen de la fase Macip del Maestro de Cabanyes. En este caso, una de dos, o existe el Maestro de Cabanyes, o, una vez más, Joanes tiene una gran parte en la ejecución de este magnífico Cristo a la columna. Porque, desde luego, el Macip de la fase Cabanyes, en solitario, de ninguna manera pudo desembocar en el Cristo a la columna de Alba de Tormes. De hecho, Tormo en 1919 y Albi en 1979 también apuntaron la posible participación de Joanes en esta tabla (cfr. ALBI, cit., 1979, vol. I, pp. 121-126).

${ }^{65}$ Cabe reconocer que en Segorbe aún no aparecen los paisajes vaporosos de la etapa de madurez de Joanes, aunque tampoco los vemos en el retablo de Fuente la Higuera, obra en solitario de Joanes entre 1547 y 1550 (ALBI, cit., 1979, I, p. 456); éste los fue incorporando, progresivamente, a partir de entonces. La verdad es que la evolución de los paisajes en el taller de los Macip (de Vicent a Joanes) es un aspecto que merece un estudio muy detenido. Lo emplazamos para otra ocasión.
} 
se trajo a Valencia procedente de Italia en 1521), pero observaremos también influencias de los Osona, de Paolo da San Leocadio, de los Hernandos, amén de diversos pintores toscanos como Fra Bartolomeo, tal vez algún precedente de Miguel Ángel, Ghirlandaio, también Garofalo y Lorenzo Costa (Albi), ecos de Perugino, grabados de la Pasión de Durero, influencias de Rafael (el Pasmo de Sicilia que Agostino Veneciano grabó en 1517), o de Marcantonio Raimondi (Planctus Mariae ). Pero veremos también, como venimos advirtiendo a lo largo de este trabajo, a Joanes; un Joanes pletórico y sabedor de sus inmensas posibilidades, como sucede, por ejemplo, en algunas partes de la Adoración de los pastores, (fig. 10), Epifanía (figs. 11 y 12), Crucifixión (figs. 13 y 14), Planctus Mariae (Santo Entierro) (fig. 15), Resurrección (fig. 16), Pentecostés (fig. 17-20) ${ }^{66}$, Dormición de la Virgen (fig. 22) San Roque (fig. 23), y San Pedro (fig. 24).

Entendemos perfectamente que nuestra propuesta se opone a un punto de vista que la tradición historiográfica ha mantenido durante muchos años, pero que precisamente ahora, a la luz de las últimas contribuciones científicas, debe modificarse. A nuestro juicio la distinción entre Macip y Joanes no admite dudas. Y si las hubiere nos parece que se disipan de inmediato a poco que comparemos, por ejemplo, la tabla de Pentecostés de Segorbe (fig. 17-20) con la homónima que Macip (fase Maestro de Cabanyes) realizó en el Retablo de San Dionisio y Santa Margarita, conservado en el Museo de la Catedral de Valencia (fig. 21). Las diferencias son inconciliables ${ }^{67}$, extremadamente notorias. Tanto, a nuestro juicio, que sólo son posibles dos vías interpretativas: o reinventamos al Maestro de Cabanyes para explicar la tabla de la catedral de Valencia, al margen de Vicent Macip, o aceptamos que en Segorbe pinta, y de forma bastante notoria y abundante, otro pintor, al que con toda justicia debemos identificar con Joan de Joanes.

Evidentemente, esto conlleva un nuevo replanteamiento historiográfico. En efecto, ahora ya no se trata tanto de estudiar la evolución del Maestro de Cabanyes (primera fase de Vicent Macip) hacia su última fase, sino de ampliar las etapas de Joanes. Hay que retrasar su cronología y empezar a plantear que Joanes inició su andadura pictórica hacia 1529. Su primera fase, pues, nace en el seno de su padre, en concreto en el retablo de Segorbe, donde sin duda emergen los primeros estilemas de clara ascendencia joanesca. Por supuesto, Macip también trabaja, abundantemente, en Segorbe, pero quien verdaderamente impulsa una incuestionable renovación plástica y figurativa es Joanes. De otro modo se nos antoja poco menos que imposible, o al menos inconciliable, una explicación convincente.

Insistimos, de todos modos, en que no es nuestra intención, por ahora, descender a detalles más concretos, entre otras cosas porque son muy otros los objetivos de este escrito, antesala de otros venideros. Nos conformamos con estimular el buen ejercicio de la crítica constructiva en el terreno de la historia del arte, y de forma aún más concreta, en el terreno de la historia de la pintura española del Renacimiento. A buen seguro que otras generaciones irán cualificando y perfeccionando nuestros actuales puntos de vista, pero precisamente por eso, y por ellas, por las mencionadas generaciones futuras, nos parece que ha valido la pena transparentar mucho de lo expresado en este escrito. Lo hemos meditado pacientemente durante más de cinco años, y desde luego nada de lo aquí expuesto se ha realizado bajo el signo de la improvisación. A la postre, y como ya fuera expresado antaño por don Leandro de Saralegui, inspirado en el sesudo padre Feijoo (en su Teatro Crítico Universal, s. XVIII), no pretendemos que lo que aquí hemos escrito "se reciba como sentencia definitiva, dada en juicio contradictorio, pues manifestándonos nuestro yerro con ingenuidad le reconoceremos y con gusto le retractaremos". ${ }^{68}$

\footnotetext{
${ }^{66}$ En relación con la figura 20 planteamos la razonable posibilidad de encontrarnos ante el autoretrato de Joanes en una edad aproximada de 25 años. Desde luego no parece que pueda ser el de su padre Vicent Macip, quien por las fechas del retablo de Segorbe ya contaría con más de 50 años de edad. A nuestro juicio la arrogancia y altivez de este penetrante autorretrato viene a confirmarnos, precisamente, que Joanes ya era un pintor totalmente emancipado en el desarrollo de la ejecución del magno conjunto de Segorbe.

${ }^{67}$ A pesar de la distancia cronológica entre ambas escenas.

${ }^{68}$ SARALEGUI, L. de : “De pintura valenciana”, Archivo de Arte Valenciano, 1962, (pp.5-12), pp. 11-12.
} 
9

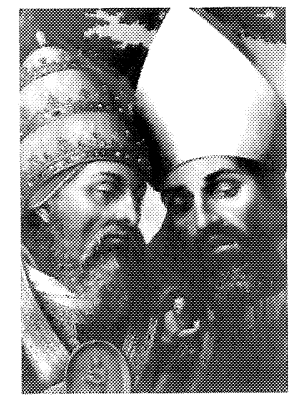

11

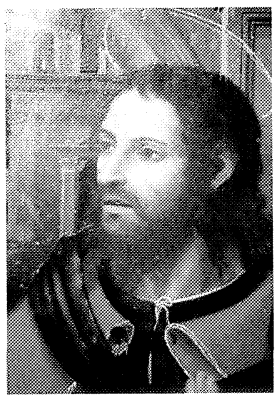

13

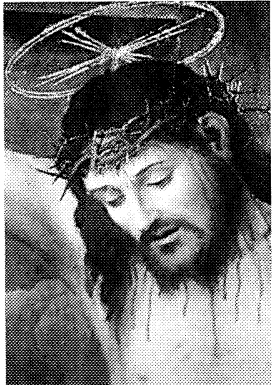

15

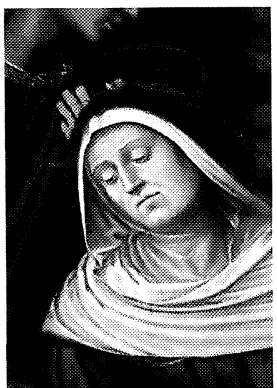

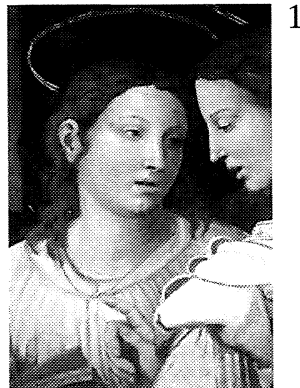
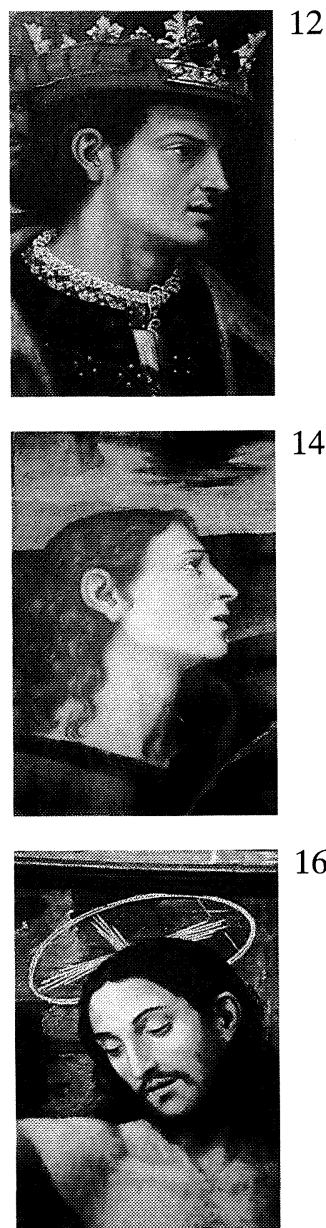

Fig. 9. Joan de Joanes: Bautismo de Jesús, detalle de San Gregorio y San Agustín. Valencia. Catedral; 1535.

Fig. 10. Joan de Joanes: Adoración de los pastores, detalle; panel del Retablo Mayor de la Catedral. Segorbe, Museo Diocesano; 1529-1532.

Fig. 11. Joan de Joanes: Epifanía, detalle; panel del Retablo Mayor de la Catedral. Segorbe, Museo Diocesano; 1529-1532.

Fig. 12. Joan de Joanes: Epifanía, detalle; panel del Retablo Mayor de la Catedral. Segorbe, Museo Diocesano; 1529-1532.

Fig. 13. Joan de Joanes: Crucifixión, detalle; panel del Retablo Mayor de la Catedral. Segorbe, Museo Diocesano; 1529-1532.

Fig. 14. Joan de Joanes: Crucifixión, detalle; panel del Retablo Mayor de la Catedral. Segorbe, Museo Diocesano; 1529-1532.

Fig. 15. Joan de Joanes: Planctus Mariae (Santo Entierro), detalle; panel del Retablo Mayor de la Catedral. Segorbe, Museo Diocesano; 1529-1532.

Fig. 16. Joan de Joanes: Resurrección, detalle; panel del Retablo Mayor de la Catedral. Segorbe, Museo Diocesano; 1529-1532. 
17

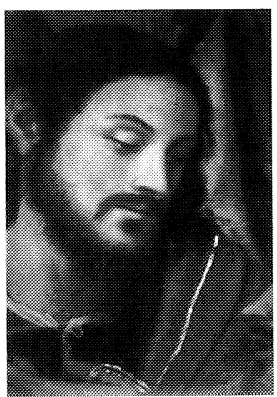

19

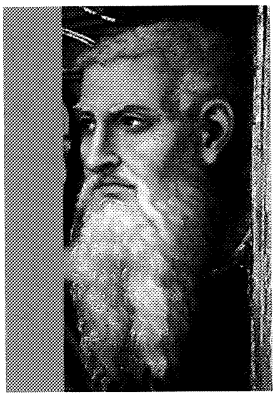

21

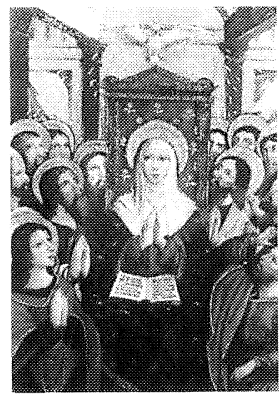

23

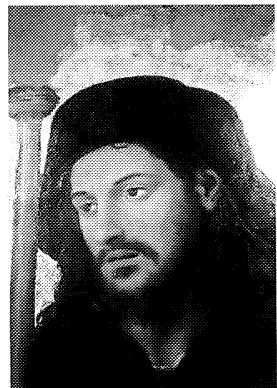

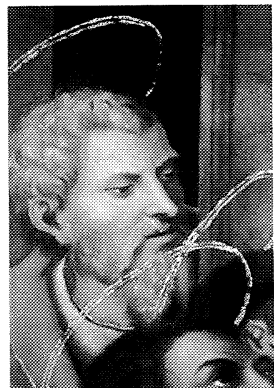

18

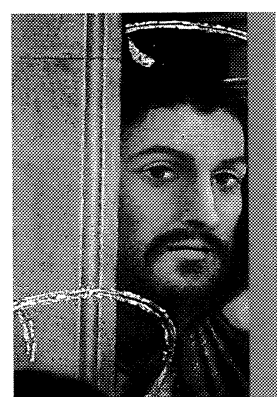

20
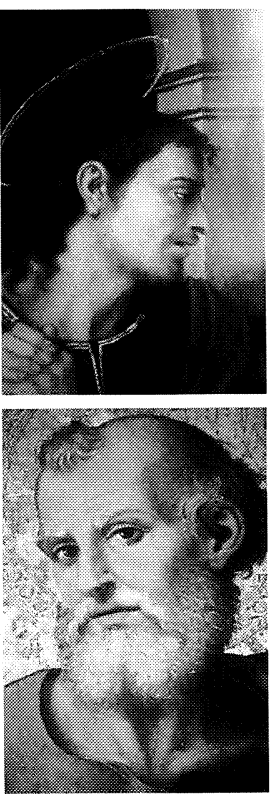

Fig. 17. Joan de Joanes: Pentecostés, detalle; panel del Retablo Mayor de la Catedral. Segorbe, Museo Diocesano; 15291532.

Fig. 18. Joan de Joanes: Pentecostés, detalle; panel del Retablo Mayor de la Catedral. Segorbe, Museo Diocesano; 15291532.

Fig. 19. Joan de Joanes: Pentecostés, detalle; panel del Retablo Mayor de la Catedral. Segorbe, Museo Diocesano; 15291532.

Fig. 20. Joan de Joanes: Pentecostés, detalle; panel del Retablo Mayor de la Catedral. Segorbe, Museo Diocesano; 15291532. Se advierte el más que probable autorretrato de Joanes, lo que vendría a confirmar la inequívoca -i altiva- intervención de Joan de Joanes en el retablo de Segorbe.

Fig. 21. Vicent Macip (fase Maestro de Cabanyes): Pentecostés, detalle; panel del Retablo de San Dionisio y Santa Margarita. Valencia, Museo de la Catedral; h. 1510.

Fig. 22. Joan de Joanes: Dormición de la Virgen, detalle; panel del Retablo Mayor de la Catedral. Segorbe, Museo Diocesano; $1529-1532$

Fig. 23. Joan de Joanes: San Roque, detalle; panel del guardapolvo del Retablo Mayor de la Catedral. Segorbe, Museo Diocesano; 1529-1532.

Fig. 24. Joan de Joanes: San Pedro, detalle; panel del Retablo Mayor de la Catedral. Segorbe, Museo Diocesano; 1529-1532. 